"Mircea cel Batran" Naval Academy Scientific Bulletin, Volume XIX - 2016 - Issue 1

Published by "Mircea cel Batran" Naval Academy Press, Constanta, Romania // The journal is indexed in:

PROQUEST / DOAJ / DRJI / JOURNAL INDEX / I2OR / SCIENCE LIBRARY INDEX / Google Scholar / Crossref /

Academic Keys / ROAD Open Access / OAJI / Academic Resources / Scientific Indexing Services / SCIPIO

\title{
ASSESSMENT OF THE IMPACT OF THE NATIONAL GRID AND OF THE MAINTENANCE PERIODS ON THE OPTIMIZATION OF THE WIND TURBINE OPERATION
}

\author{
Gheorghe SAMOILESCU ${ }^{1}$ \\ Florentiu DELIU ${ }^{2}$ \\ Adelina BORDIANU ${ }^{3}$ \\ Alina BARBU 4 \\ ${ }^{1}$ Captain Professor engineer, Ph.D, "Mircea cel Batran" Naval Academy, Constanta \\ ${ }^{2}$ Engineer Ph.D , "Mircea cel Batran" Naval Academy, Constanta \\ ${ }^{3}$ Lecturer engineer Ph.D, University "Politehnica" of Bucharest \\ ${ }^{4}$ Lecturer Ph.D, Constanta Maritime University
}

\begin{abstract}
The upsurge in the value of wind energy in Romania may have occurred due to a constructive development of wind turbines, their dimensions and the increase in their number of units in wind farms. The modern design of large wind turbines, corroborated with an appropriate wind speed leads to a significant production of green energy. In order to obtain a greater amount of energy, modern turbines are fitted with many devices which are exploited by high-tech electronic circuits. Instruments of remote detection, measurement devices and control processes of the main measurement systems are based on various types of electronic apparatus. These appliances are very sensitive to tension variation caused by abnormal conditions of turbine operation and by the national electrical grid which the wind farm is connected to. The paper aims at providing an assessment of a wind farm registers as well as a set of methods meant to overcome such obstacles related to designing large wind turbines. Similarly, the paper offers a classification of the various types of abnormalities that appear in the installation connected to the electric grid, such as a sudden power cut, unplugging or tension variation. The difficulty of such an impact is to be determined for every type of disorder associated to electronic glitches occurring in wind turbines.
\end{abstract}

Key words: wind turbines, solar energy, electronic apparatus, electric grids

\section{Introduction}

Wind energy technology is an overriding concern of this century, experiencing a rapid growth and being considered to be one of the present-day flourishing technologies. Devising this technology is not limited to a significant increase in size of modern units, but also includes the reliability and availability of current installations. Competition between manufacturers has played a remarkable role in establishing a large market for this industry and attracting newcomers to this field. Therefore, the number of wind farms, equipped with multi-megawatt class turbines has skyrocketed in the last decade in Romania. Parallel to the development of this technology, there has been a lack of long-term experience regarding the operation and maintenance of large wind turbines. It is therefore necessary to evaluate these turbine availability by analyzing the defects and maintenance records for the examined wind farms. Unfortunately, only a few scholars have discussed the performance and reliability of existing wind turbines [4-6].

The location of a wind farm is usually selected based on several studies including a long history of wind availability in the area and at least one year of continuous measurement of wind speed and direction. These datasets are used to estimate the annual yield of the farm and future turbine performance. However, the assessment studies are usually shut down or greatly reduced when the wind farm starts operating. Many researchers believe that there is no purpose for further evaluation because the farm was already set up. Unfortunately, this assumption is not true for several reasons.

First, the existing data produced by the wind farm are real and they can be used to assess expectations and previous assumptions on the turbine performance. Second, all existing wind farms are either upgraded or expanded in the future.

Therefore, the assessment in one place is more logical and real than relying on the pre-setup stage. Finally, the assessment of existing turbines in terms of reliability and their performance is important in order to make any improvements or changes in energy production, especially in a deregulated market. The increased research in this field was either general or focused only on the reliability of wind turbine parts $[7,8]$. Another ignored problem is the long-term impact on the performance of the turbine of electricity grids and its production. The availability of wind turbines is 


\begin{abstract}
"Mircea cel Batran" Naval Academy Scientific Bulletin, Volume XIX - 2016 - Issue 1
Published by "Mircea cel Batran" Naval Academy Press, Constanta, Romania /I The journal is indexed in: PROQUEST / DOAJ / DRJI / JOURNAL INDEX / I2OR / SCIENCE LIBRARY INDEX / Google Scholar / Crossref /

Academic Keys / ROAD Open Access / OAJI / Academic Resources / Scientific Indexing Services / SCIPIO
\end{abstract}

usually based on the performance of the turbine itself. The impact of the electric grid in reducing wind availability of these units is rarely taken into account.

Even if looked into it is not deeply investigated. The reason for ignoring this factor is the difficulty of assessment, the degree of impact on wind farms. On the other hand, the presence of wind farms in remote areas with low, radial electricity distribution grids exacerbates the problem. The aging of distribution systems increases the disconnect rate and reduces the reliability of power cables and generated units, including wind turbines. Thus, more disconnections of these turbines will lead to lower production, performance and reliability of these generating units. Instead, most research is now focused on the impact of wind turbines on grids, and not vice versa. The main objective of this paper is to present the impact of the distribution grids on the performance of the wind farm. This topic should be investigated in order to address the main problems that can cause a drop in performance of wind turbines connected to the grid, to make a real assessment, examination and grading of long-term problems caused by electrical grids. Related data, collected from wind farms were considered as the main source used for this study. To assess the impact of the electrical installation connected to the grid on the performance of a wind farm, it is necessary to weigh the defects caused by the latter, leading to a disruption of farms in terms of lost production and prolonged outage, although the records of breakdowns are available in the examined farms, they are passive data sets regarding the definition of causes or links between these outages and the reduction of electricity production.

Therefore, it was necessary to define the planned and unplanned shortcomings of outages in wind farms, based on the above factors. This was the main focus of the current study. The tool to achieve this goal depends on statistical principles. The paper has tried to illustrate a way of quantifying the hours lost and undelivered energy of a wind farm while it is available for operation under the influence of suitable wind speed. Finally, there is no clear agreement between the owners of wind farms and electric utilities on these issues and no defined approach to solve them. Therefore, there is a lack of coordination and interface between wind farms and electric utilities, negatively affecting the energy production.

This is done by identifying the main problems of grid-connected installation causing closure of the turbine and by evaluating the duration and frequency of these defects. The paper is based on the analysis of wind farm registers of unplanned outages of wind turbines for a period of 5 years, however, several obstacles have been encountered with this approach. First, the errors in the registers, which should specify the causes of turbine shutdowns and yet they were unclear in many cases. This appears under „unknown defects". Secondly, the records do not have a bridge to make the connection between defects or other events, and the database is available for the case study only for statistical purposes. Thirdly, there is a lack of technical studies to investigate these defects and to improve turbine performance.

This study attempts to quantify the problem of calculating the impact of specific faults and determine their annual frequency of occurrence. After describing the wind farm under study, the paper will present the causes and general consequences of turbines breakdowns. In this context, the main categories of turbine stop triggers will be studied based on the actual number of hours during which the turbine is inoperative. Daily records are used to determine fault duration, the hours of maintenance and the wind turbine downtime. This document focuses on the time periods in which the turbine is halted due to grid- initiated failures and classifies components malfunctions, the causes and incidence of these failures.

\section{Description of a wind farm in Dobrogea area} (Tulcea County)

The wind farm is located on the hills of Tulcea country consisting of 5 wind turbines, Vestas 225 $\mathrm{kW}$, which have been installed and put into operation in May 2010 [12]. The average wind speed was measured in this area and is $6.3 \mathrm{~m} / \mathrm{s}$. The automatic functioning of the turbine enables the turbine controller to assess the environmental, mechanical and electrical conditions at start-up, operation, pause or closing of the unit. The control system has two parts: upper and lower controllers. The controller is located in the upper basket, while the lower controller is located in the underground panel in the basement of the tower. The farm operator is responsible for organizing the activities on perimeter and active performance reports of the wind farm.

\section{Consequences of failures}

The efficiency of the conversion system of wind energy depends on the average wind speed. Much of the uncertainty in terms of turbine failure is related to its downtime caused by external conditions. Therefore, if the turbine is hampered by a faulty grid or a failure of the communication system, it will automatically display as an external condition, whereas if the turbine has stopped due to temperature overshoots or generator speed it will be classed as an internal turbine failure. 


\begin{abstract}
"Mircea cel Batran" Naval Academy Scientific Bulletin, Volume XIX - 2016 - Issue 1
Published by "Mircea cel Batran" Naval Academy Press, Constanta, Romania /I The journal is indexed in: PROQUEST / DOAJ / DRJI / JOURNAL INDEX / I2OR / SCIENCE LIBRARY INDEX / Google Scholar / Crossref /

Academic Keys / ROAD Open Access / OAJI / Academic Resources / Scientific Indexing Services / SCIPIO
\end{abstract}

The turbine is affected by internal defects caused by the device itself, and external defects caused by the electrical grid. Internal defects are those defects caused by mechanical and electrical systems of the turbine, such as speeding or excitation, excessive temperature, swivel cables and other control issues.

External damages include loss of communication, wrongful setting of the relay on the grid, imbalance of symmetrical and asymmetrical short circuits loads voltage, over-voltage and under frequency disturbances. However, human errors could be classified as internal and external faults, depending on where they occur. Breakdowns or closures frequency wind turbines are affected by operational conditions and design complexity. Major defects are generally classified as human error, design failure or wear off of a component of the operational system. The factors affecting the breakdown frequency include speeding, excessive vibration, rotation error and sync failure.

Although it is assumed that turbine failure due to an external fault will be restarted without a major repair, in many cases the external consequences of malfunctions can be very severe. On the other hand, internal causes of faults are associated with long-term shutdowns and prolonged time to repair and restart.

\section{Study results}

Although the obtained results are directly linked to the case study of the investigated wind farm, a series of debated issues may be beneficial and applied to other plans of wind farm. The annual variation The annual change in the number of maintenance hours spent and lost due to faults in the entire wind farm is shown in Figure 1, unfortunately, the inoperative time is associated with faults has increased dramatically in recent years. By inoperative time we mean the accalmy when there is no wind or there is a gust of wind but the speed is not sufficient to produce energy. Regarding Fig. 1, there are two sources of stopping the turbines other than during accalmy.

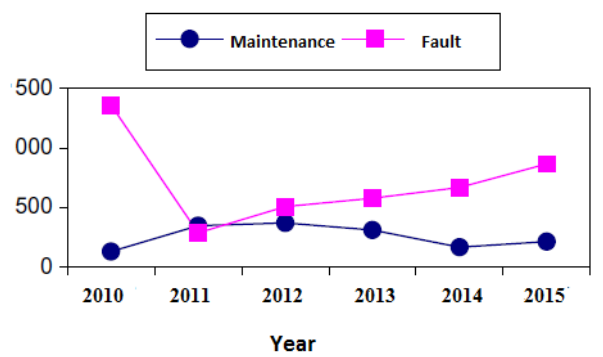

Fig.1

The first is maintenance, that has been growing in the first three years because of specific problems with the equipment installed. When the issues have been taken care of, the time spent on maintenance began to shorten year after year. More experience is gained by people who operate and maintain these facilities. However, the drop rate is low. The failure curve has different modes of variation. If the two curves are evaluated simultaneously, it is possible to conclude that the hours lost due to faults are growing at a higher rate than the decrease due to bettered maintenance. The growth rate in the failure curve is greater than the decline rate of in the maintenance curve that could reduce the longterm performance and availability of the system. Although it is difficult to control the time lost due to lack of wind, it is possible to manage the maintenance time. This can be done by investigating the monthly distribution of these inoperative hours. The monthly averages of critical hours is calculated taking into account all turbine shutdowns that occurred in the same month during the period considered.

The summer months of June to August are considered wind months during the year and therefore they are very important for energy production and plant profitability. On the other hand, although the energy intake of these turbines is limited as compared to high power conventional grids, it is highly appreciated in this period. With an average temperature of more than $35 \mathrm{C}$, the grid is put under stress during hot days due to a high load demand during the summer with electric fans, water pumps and air conditioning

Therefore, the coincidence of how wind energy is produced and the production variation upload increases the importance of these farms. Following the above facts and arguments, regular inspections and condition monitoring are needed to reveal serious problems that cannot be detected automatically by the operator, and are recommended to be made in the summer.

Less urgent maintenance works should be performed during the spring or fall. This reflects the fact that the number of hours lost in the summer months should be higher than in other months as energy production was used to designate the month with the lowest energy production as reference month and the inoperative hours during the other months are calculated accordingly. Figure 2 shows the monthly production of wind energy in Tulcea wind farm for an average value of three years. 
"Mircea cel Batran" Naval Academy Scientific Bulletin, Volume XIX - 2016 - Issue 1

Published by "Mircea cel Batran" Naval Academy Press, Constanta, Romania // The journal is indexed in: PROQUEST / DOAJ / DRJI / JOURNAL INDEX / I2OR / SCIENCE LIBRARY INDEX / Google Scholar / Crossref /

Academic Keys I ROAD Open Access / OAJI / Academic Resources / Scientific Indexing Services / SCIPIO

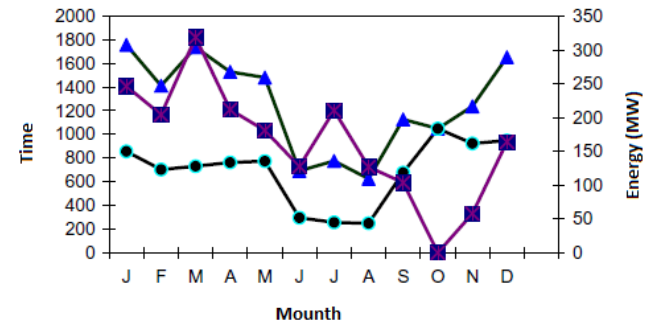

Fig.2

Provided the above mentioned concept is applied during windless periods, the estimated, real amount of energy is presented in figures 3,4 and 5. Summer months, june through august are winds months during which the operation of wind turbines is increased. This means that the average production per hour is increased. Consequently, it is preferable not to perform any maintenance or exposure to any failure during this period of time. Consequently, with a view to determining this quantity we have used a reference month. The month with a minimal production has been used as reference in this case.

Figures 3-5 have been drawn based on this concept. It is interesting to notice that, despite the fact that summer months are still interpreted depending on the least hours of accalmy, the maximal value for accalmy has been changed from october to january.

In spite of all this, the months that breach this general tendency must have a reason for doing so, other than the accalmy which affects the energy production. The curve describing the maintenance moment in Figure 4 shows a significant increase of the estimated summer months as compared to the other seasons. Unlike the moment of accalmy, the estimating effect of the concept is valuable here proving us with the possiblity to switch maintenance to periods with weaker winds.

Fig. 5 describes the malfunction moment which is influenced by two factors: turbine performance and grid reliablity.

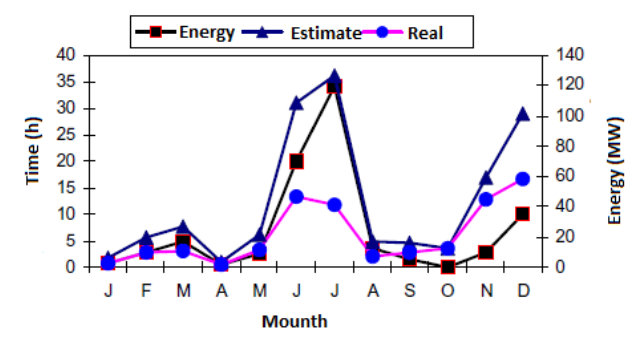

Fig. 3

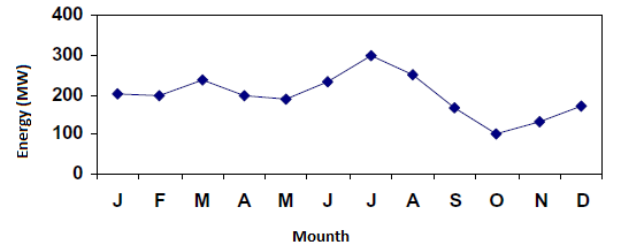

Fig.4

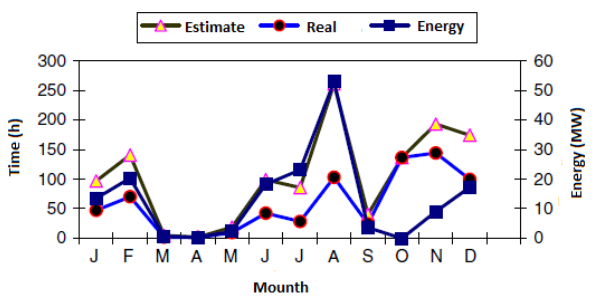

Fig. 5

Therefore, part of this curve is adapted to the grid conditions, making the entire system not to optimally function stress in winter and summer. The most significant change resulting from determination was switching the malfunction time from October to August. This means that although the number of hours lost in August is lower than those lost in October, their importance is much greater. This underlines the absolute need to reduce the turbine downtime during periods of good wind. The equivalent energy, corresponding to the difference between the estimated and actual hours can be used to demonstrate the importance of ineffective management associated with closing hours of wind turbines. The value of the equivalent energy is basically influenced by the difference between the actual and the estimated hours. Therefore, the power curves behave similarly to the curves of the estimated time during the associated months with a big difference between the estimated and the curves. If maintenance tasks are reported to less windy seasons and the number of faults is reduced by improving network reliability, the difference between the estimated and actual times will be reduced and the energy equivalent will be low.

The impact of grid failures on wind turbine operation

In recent years, the emergencies occurring due to problems caused by faults or voltage variations in the distribution grid have definitely increased. Most breakdowns associated with these disorders occur due to grid failures, especially when turbines are automatically reconnected to the grid after many hours of disconnection. In many cases, the turbine succumbs during synchronization with the grid due to low temperature lower or higher processor. The response to grid failures are not limited to energy loss during turbine breakdown, which sometimes remain for several hours, but 
"Mircea cel Batran" Naval Academy Scientific Bulletin, Volume XIX - 2016 - Issue 1

Published by "Mircea cel Batran" Naval Academy Press, Constanta, Romania // The journal is indexed in: PROQUEST / DOAJ / DRJI / JOURNAL INDEX / I2OR / SCIENCE LIBRARY INDEX / Google Scholar / Crossref /

Academic Keys / ROAD Open Access / OAJI / Academic Resources / Scientific Indexing Services / SCIPIO

expands to include other losses such as the cost of repairs and component replacements. Electronic boards included in the turbine control system are very sensitive to voltage variations associated with defects of the grid. These boards are frequently put under stress immediately after reconnecting to the grid. In order to reduce the impact of wind farm performance, all major types of faults must be categorized and evaluated based on frequency and time.

Damages are classified according to their sources Fig. 6. In order to explain the increased frequency of disturbances presented in the annual variation of the turbine in 2015, suffice it to mention that this increase is attributed to grid-related disorders affecting the turbine operation. The tension variation after connecting the turbine to the grid makes more electronic boards turbine to be damaged and to stop for dozens of hours. This phenomenon is rather common. Initial grid malfunctions tend to have a continuous increase as compared to turbine failures. The presence of "'Jane Doe" classes of faults increases the uncertainty regarding the impact of the grid on the performance of the turbine because some of these unknown errors are supposed to be initiated by the grid itself. Generally, the main turbine malfunctions, and related grid disorders in particular, have been analyzed and distributed according to the number of their occurrence. Despite the long duration of the failure, its occurrence rate is an important indicator of certain weaknesses of the turbine itself $[16,17-18]$.

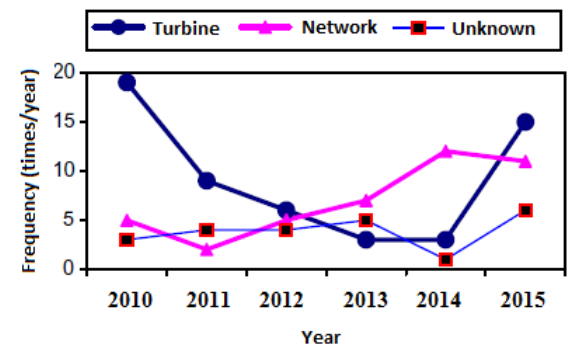

Fig. 6

The average value of a failure is calculated as average annual percentage of that failure to the total number of failures. The disorders associated with the pitch of the reference propeller, the control system of the grid and the turbine represent on average more than $80 \%$ of the wind farm malfunctions. Grid failure analysis shows that more than two thirds of malfunctions that cause grid disconnections associated to turbine cut off from the mains grid. Shutdowns due to voltage variation and casual switch operation because of known and unknown reasons are fairly common events. To assess the severity of various faults, the closing time due to disturbances each year is accumulated and then calculated as a percentage of the total time wasted due to those disturbances. For the period studied, an average value is determined for each annual percentage. Figures 8 and 9 show the distribution in time of these faults. A comparison made between frequency and period of distribution of fault events reveals two important points.

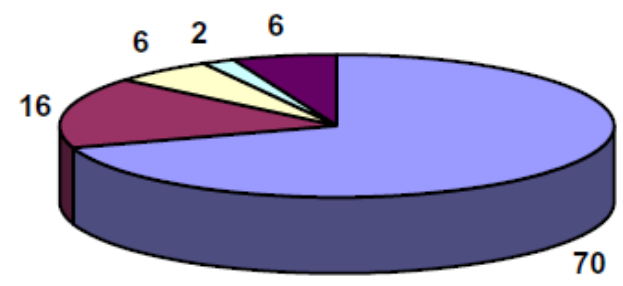

Fig. 7

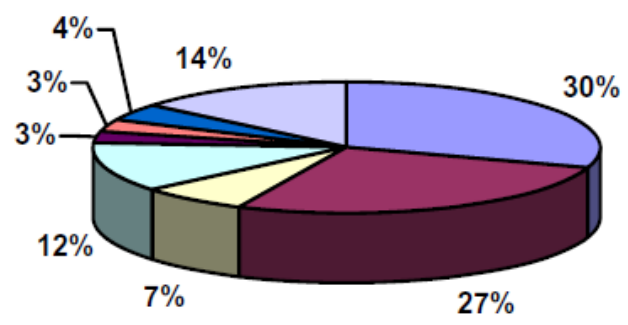

Fig.8

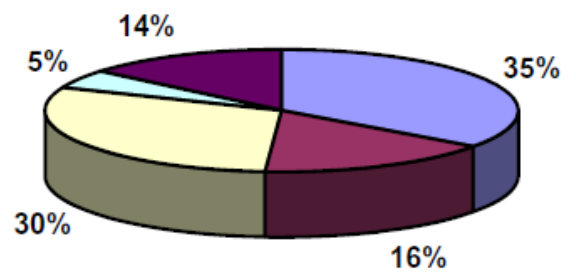

Fig.9

First, there is general agreement among major faults, yet the percentage of the share quota for the same type of failure is different. This means that the main malfunctions prevail in time and frequency distribution. However, some faults do not occur frequently, but disruption of this type can cause a loss of hundreds of hours of operation. Secondly, the discrepancy between time and frequency distribution is clearer for grid faults as for the whole range of turbine faults. In many cases a brief but frequent malfunction can lead to serious events which may lead to turbine shutdown for several hours. Frequent start-stop grid-initiated actions may lead to switch turn-on, to explosion of the main fuses or even damage of electronic cards $[17,18]$. 


\begin{abstract}
"Mircea cel Batran" Naval Academy Scientific Bulletin, Volume XIX - 2016 - Issue 1
Published by "Mircea cel Batran" Naval Academy Press, Constanta, Romania /I The journal is indexed in: PROQUEST / DOAJ / DRJI / JOURNAL INDEX / I2OR / SCIENCE LIBRARY INDEX / Google Scholar / Crossref /

Academic Keys / ROAD Open Access / OAJI / Academic Resources / Scientific Indexing Services / SCIPIO
\end{abstract}

The distribution of inoperative hours while helping to re- schedule maintenance activities to avoid carrying them out in the wind. The routine is applied to components, such as brake systems, oil and transmission assembly screws, lubrication bearings, and changing oil filters can be done while the turbine is put in standby waiting for fair wind. One of the activities rather difficult to schedule is the maintenance of the grid interface, including high voltage equipment. These elements are part of the distribution system, which has its own maintenance program. To reduce the unplanned downtime in lost hours it is necessary to inspect the severity of the fault. The impact of any failure is measured by its frequency and duration $[14,15]$. Therefore, absolutely all defects are analyzed according to their repetitive nature and duration. The correlation between different faults is an important step in establishing a prediction system able to protect turbine from major disorders. This approach is in line with the suggestions of other researchers about preventive maintenance and monitoring conditions to reach the scheduled lifetime of the turbine without serious damage.

\title{
CONCLUSIONS
}

The monthly variation in wind energy production of the wind farm was used for the classification of inoperative hours due to grid and turbine malfunctions, according to their importance. The new distribution of these hours was used to compare the impact of various faults causing turbine shutdown. The importance of rescheduling maintenance activities to be shared with the new estimated time distribution was also discussed. In the end, frequency and duration of the most common types of failures were analyzed and compared, aiming at setting up a future approach for broader prediction techniques.

\section{BIBLIOGRAPHY}

[1] Wagner A. Prospects for wind energy in the European Union by 2010. In: Proceedings of the EWEC; 1999. p. 13-7.

[2] Rohrig K. Online monitoring of 1700 MWwind capacity in a utility supply area. In: Proceedings of the EWEC; 1999. p. 444-7.

[3] Jaatinen E.V. Condition monitoring of a wind turbine. In: Proceedings of the EWEC; 2001. p. $1036-8$.

[4] Hahn B. Reliability assessment of wind turbines in Germany. In:Proceedings of the EWEC; 1999. p. $13-7$.

[5] Durstewitz M, Wengler R. Analyses of generator failure of wind turbines in Germany. 250 MW wind programme. Kassel: ISET; 1998.

[6]Deliu F., Transitory phenomenons into naval electrical equipment hybrid powered, POLITEHNICA Timişoara, 2011

[7] Gerdes G, Santjer F. Power quality of wind turbines and their interaction with the grid. In: Proceedings of the EWEC. Thessaloniki, Greece; October 10-14, 1994. p. 1112-5.

[8] Bendel U, Schneider B. Living with mistakes: a new approach to a quality management system for WTGs components. In: Proceedings of the EWEC; 1999. p. 703-5.

[9] Boulaxis NG, Papathanassiou SA, Papadopoulos MP. Slow voltage variationassessment in distribution networks with wind penetration. In: Proceedings of the EWEC; 2001. p. 1200-3.

[10] Carlson O, Hylander J, Thorborg K. Survey of variable speed operation of wind turbines. In: Proc. EWEC; 1996. p. 406-9.

[11] Larsson $\AA$. Flicker emission of wind turbines during continuous operation. IEEE Trans Energy Convers 2002;17(1):114-8.

[12] VESTAS V27-225 kW Instruction Manual, Item No 941154, 1993. p. 15-7.

[13] Manwell JF, Rogus A, Abdulwahid U, EillisA.Wind turbine gearbox evaluation.In: Proceedings of the EWEC; 1999.p.825-8.

[14] Söker H, Seifert H. Preventive load monitoring and conditions monitoring -how to reach the scheduled service life without financial damage. DEWI Mag 2003;23:66-71. (August).

[15] Ackermann T. Wind Power in Power Systems. West Sussex: John Wiley and Sons Ltd.; 2005.

[16] Gjengedal T. Integration of wind power and the impact on power system operation. In: Proceedings of the power engineering, large engineering systems conference; May 2003. p. 76-83.

[17] AbderrazzaqM.Energy production assessment of small wind farms.Int J Renew Energ - Elsevier 2004;29(April):2261-72.

[18] - M.H. Abderrazzaq, O. Aloquili, Energy Conversion and Management, Evaluating the impact of electrical grid connection on the wind turbine performance, 2008

[19] CEGCO log book for operation and maintenance a wind farm. 